\title{
Diálogos necessários: neurociência, emoções e a formação inicial de professores
}

\author{
Aline Resende Gomes; Pedro Donizete Colombo Junior *
}

Resumo. Estudos no campo da neurociência tem evidenciado a intima ligação entre momentos emocionais e construções cognitivas, evidenciando que o percurso educacional, em seus diferentes contextos, é um processo inseparável de aspectos emocionais. Hoje já não é possível pensar a formação inicial de professores sem considerar tais interconexões, em especial os Estágio Curricular Supervisionado (ECS), importantes momentos pedagógicos do processo formativo do professor. A presente comunicação tem como objetivo investigar as emoções que expressadas por licenciandos (estagiários) em Física e Ciências Biológicas da Universidade Federal do Triângulo Mineiro (UFTM), Minas Gerais, Brasil, em suas primeiras vivências didáticas em sala de aulas, as regências. A pesquisa de natureza qualitativa, abarcou observações e gravações em áudio e vídeo das regências, articulando-as com subsequentes entrevistas semiestruturadas. No campo metodológico, adotou-se as ideias das Entrevistas de Explicitação (EDE) como prática auto reflexiva dos estagiários, fomentada pelas construções teóricas de Paul Ekman sobre emoções. Os resultados apontam que um dos maiores desafios enfrentados pelos estagiários é saber como lidar com suas emoções frente as diferentes situações que surgem no contexto escolar. Algumas emoções mais frequentes expressadas pelos estagiários foram medo, surpresa, tristeza e raiva. Como forma de superá-las, em muitos casos, optavam por afastar-se das situações vivenciadas em oposição ao enfrentamento. Em uma autorreflexão, os estagiários relatam que mapear e discutir as emoções (às vezes ocultados pela prática) foi de grande valia para refletirem sobre estágios de regência.

Palavras-chave: neurociência; emoções; formação inicial de professores; estágio curricular supervisionado.

\section{DIÁLOGOS NECESARIOS: NEUROCIENCIA, EMOCIONES Y FORMACIÓN INICIAL DE PROFESORES}

Resumen: Los estudios en el campo de la neurociencia han evidenciado la estrecha conexión que existe entre los diversos estados emocionales y las construcciones cognitivas en diferentes contextos educativos, evidenciando que el proceso educativo es un proceso inseparable de los aspectos emocionales. Hoy ya no es posible pensar en la formación inicial de profesores sin considerar tales interconexiones, en especial los que se refieren a la pasantía curricular supervisada. La pasantía curricular supervisada es una importante parte pedagógica en el proceso formativo del profesor. Esta investigación pretende tratar las emociones de los estudiantes de grado en

\footnotetext{
* Universidade Federal de Triângulo Mineiro (UFTM), Brasil.
} 
Física y Biología de la Universidad Federal de Triângulo Mineiro (UFTM), Minas Gerais, Brasil, durante sus primeras experiencias impartiendo clases en las pasantías. La investigación, de naturaleza cualitativa, abarcó observaciones y grabaciones en audio y video de los estudiantes, articulándolas con entrevistas semiestructuradas. En el campo metodológico se adoptaron las experiencias de las entrevistas de explicación como práctica auto reflexiva de los estudiantes, fundamentadas en las construcciones teóricas de Paul Ekman sobre las emociones. Los resultados apuntan que uno de los mayores desafíos enfrentados por los alumnos es saber cómo manejar sus emociones frente a las diferentes situaciones que surgen en el contexto escolar cotidiano. Algunas de las emociones más frecuentes expresadas por ellos fueron miedo, sorpresa, tristeza y rabia. En muchos casos, estos optaban por evitar estas situaciones vivenciadas en vez de enfrentarlas. En una autorreflexión, los alumnos relatan que discutir las emociones fue de gran valor para reflexionar sobre cómo empezar la carrera docente, en especial en las pasantías supervisadas.

Palabras clave: neurociencia; emociones; formación inicial de profesores; pasantía curricular supervisada.

\section{NECESSARY DIALOGUES: NEUROSCIENCE, EMOTIONS AND INITIAL TEACHER TRAINING}

Abstract. Studies of neuroscience have evinced the intimate connection between emotional moments and cognitive constructs in different educational contexts, evincing that the educational path is an inseparable process of emotional aspects. In this regard, it is no longer possible to think about initial teacher training without considering such interconnections, especially the supervised training course, which is an important pedagogical moment. This paper aims at investigating the emotions of Physics and Biological Sciences teachers-to-be at the Federal University of the Triângulo Mineiro (UFTM), Minas Gerais, Brazil, in their first didactic experiences in classroom. This qualitative research included class observing and audiovisual recordings of the student teacher interns, articulating them with subsequent semistructured interviews. In the methodological field, we adopt the ideas of the Explicitation Interviews and the theoretical constructs of Paul Ekman about emotions. The results show that one of the greatest challenges faced by pre-service teacher when they begin in classrooms is to know how to deal with their emotions before different situations that arise. Some of the most frequent emotions expressed by the pre-service teacher during the classes were fear, surprise, sadness and anger. As a way of overcoming them, in many cases, they chose to move away from situations experienced as opposed to confrontation. The pre-service teacher report that mapping and discussing emotions it has been valuable in especially about yours first classes.

Keywords: neuroscience; emotions; pre-service teacher; supervised training course. 


\section{NEUROCIÊNCIAS E FORMAÇÃO INICIAL DE PROFESSORES}

Nas últimas décadas tem se intensificado as discussões e investigações sobre os avanços da neurociência vinculados aos processos de ensino e aprendizagem em âmbito educacional. Também tem crescido exponencialmente as discussões sobre a formação inicial de professores, frente as novas demandas colocadas pela sociedade. As rápidas e contínuas mudanças de perfis dos estudantes colocam-se como desafios a serem enfrentados na formação inicial de professores e afetam diretamente o pensar "ser" professor. Vivemos a era digital, na qual cada vez mais nos deparamos com estudantes de uma geração conectada pelas mídias digitais, que preza pelos imediatismos de uma sociedade moderna e que se colocam como impacientes frente a questões temporais, essência dos processos educacionais. Um cenário que pode levar a um anacronismo educacional, em que conceitos e sistemáticas educacionais tornar-se rapidamente obsoletas para os 'efêmeros' constructos pedagógicos do tempo presente.

Assim, a rápida aproximação entre o professor em formação com seu futuro ambiente de trabalho se mostra como um fator essencial para os desafios da carreira docente atual. Papel este, na maioria das vezes, que fica sob a incumbência dos Estágio Curricular Supervisionado (ECS) e que, no cenário educacional brasileiro, tem início a partir da metade dos cursos de formação inicial de professores. O ECS é um importante momento pedagógico na construção de aprendizagens significativas, integrante do processo de formação inicial de professores, propiciando o desenvolvimento de saberes profissionais e permitindo uma visão mais abrangente da atuação do licenciado (Costa e Gonçalves, 2004).

Fato é que a formação in loco, propiciada pelos ECS, revela aspectos velados da formação inicial docente, como angústias, medos e insegurança do futuro professor frente a realidade escolar, ou seja, são circunstancias que explicitam diferentes emoções expressadas pelos iniciantes em seus primeiros contatos com as salas de aulas. Evidenciando, contudo, que processos formativos são processos emocionais, ou seja, não se aprende sem emoção (Carvalho 2011, Bortoli e Teruya 2017).

Aprender a lidar com a realidade escolar e, com as emoções que dela derivam, é um fato a ser encarado pelos futuros professores, carecendo inclusive de maior atenção por parte das instituições formadoras. Segundo Shulman (2015) os aspectos afetivos das práticas do ensino são relevantes, uma vez que os conhecimentos que o professor transmite não são passivos de separação dos seus próprios estados emocionais e motivações, de modo que acabam por influenciar a aprendizagem de seus alunos. Estudos da neurociência caminham no sentido de mostrar que aspectos emocionais são 
inseparáveis de aspectos cognitivos, ou seja, já não é possível em pleno século XXI pensar a formação inicial de professores sem considerar tais interconexões (Lopes e Couto, 2014).

O objetivo desta comunicação é revelar parte dos resultados de uma investigação que buscou identificar as emoções de professores em formação inicial de cinco cursos da área de Ciências as Natureza e Matemática (Física, Química, Ciências Biológicas, Matemática e Educação do Campo) da Universidade Federal do Triângulo Mineiro (UFTM), Minas Gerais, Brasil, em suas primeiras vivências didáticas em salas de aulas - aulas de regências nos ECS. Devido a extensão do texto optamos, neste recorte de pesquisa, por apresentar os resultados extraídos dos cursos de licenciatura em Física e licenciatura em Ciências Biológicas. Os participantes foram dois licenciandos (estagiários) que cursavam a disciplina obrigatória "Orientação e Estágio Curricular Supervisionado II" (ECS II), outorgada no $6^{\circ}$ semestre, momento em que ministraram suas primeiras regências em salas de aula.

No cenário brasileiro, o ECS é uma exigência da Lei de Diretrizes e Bases da Educação Nacional (Brasil, 1996) nos cursos de formação de professores. Segundo a resolução n ${ }^{\circ}$ 2/2015 do Conselho Nacional de Educação (Brasil, 2015) os cursos de licenciaturas devem contemplar uma carga horária mínima de 3200 (três mil e duzentas) horas, sendo 400 (quatrocentas) horas destinadas ao ECS, em acordo com o projeto pedagógico do curso. Em particular, nos cursos de licenciatura da UFTM os estágios são divididos em quatro vivências, sendo iniciado após a conclusão da primeira metade dos cursos.

No ECS I, o foco recai sobre a vivência com a Educação Não Formal, por exemplo, em ações realizadas em centros de ciências, museus, zoológicos. Os ECS II e III refletem os primeiros passos dos futuros professores em sala de aulas, tendo como foco as séries finais do Ensino Fundamental ( $5^{\circ}$ ao $9^{\circ}$ ano) e o Ensino Médio ( $1^{\circ}$ ao $3^{\circ}$ ano), respectivamente. Por fim, o ECS IV tem como foco o desenvolvimento de um objeto educacional a ser aplicado em uma das séries em que o licenciando estagiou. No que tange a carga horária dos estágios, o licenciando deve cumprir 120 (cento e vinte) horas/aula, divididas em 15 (quinze) horas/aula presenciais de orientação com o professor orientador (na Universidade) e 105 (cento e cinco) horas/ aula integrando preparação e ações na escola, sob supervisão do professor supervisor (na Escola). Integram tais ações: observações em salas de aulas; reconhecimento do contexto escolar; elaboração dos planos de aula; relatórios e registros escritos e regências sob a supervisão do professor na escola. 
É justamente nesta última ação que se situa a presente investigação. Os momentos de regências são períodos impares na formação do licenciando, visto que os primeiros passos rumo a profissão que escolheu colocam-se como um cenário propicio para o desencadear de inúmeras emoções. Sobre este aspecto, Carvalho menciona que,

$\mathrm{Na}$ sala de aula, o que se fala e como se fala constituem elementos desencadeadores de pensamentos e raciocínios. Tomando como exemplo as informações visuais e auditivas veiculadas em um dado recurso didático, bem como o comportamento docente, eles criam circunstâncias capazes de configurar determinada identidade emocional, em virtude de pensamentos e memórias, que evocam lembranças e manipulam a interpretação na mente (Carvalho, 2011, p. 545).

Buscamos mapear e trazer à tona as emoções vivenciadas pelos licenciandos no momento de ECS e propiciar momentos de reflexão sobre suas práticas enquanto futuros professores, a partir do método da "entretien d'éxplicitation" ou Entrevista de Explicitação (EDE) (Vermesch, 2003), fomentada pelos constructos teóricos de Paul Ekman sobre emoções (Ekman, 2011). Ademais, almejamos contribuir com a formação de professores, visto que não encontramos na literatura da área trabalhos que versam sobre a temática ECS e emoções (Gomes e Colombo Junior, 2018).

\section{EMOÇÕES NO CENÁRIO DA FORMAÇÃO DE INICIAL DE PROFESSORES}

As emoções podem ser consideradas uma das formas mais importantes de comunicação humana, eclodindo de sentimento e sendo muitas vezes involuntária. É por meio das emoções que podemos experienciar e expressar sentimentos na interação com outros, possibilitando, inclusive o interpretar das expressões emocionais daqueles com quem interagimos (Strongman, 2004). Apesar de inúmeras definições, sob a ótica da neurociência, as emoções são reações fisiológicas e psicológicas que influenciam na compreensão, conhecimento e desenvolvimento do indivíduo (Murray, 1973). Destaca-se que o número de pesquisas na área de neurociências tem aumentado consideravelmente nos últimos anos, em especial à temática "emoções" relacionadas ao contexto educacional (Borrachero et al., 2014).

[...] a neurociência - enquanto um ramo do conhecimento que envolve várias áreas como, por exemplo, a neurologia, a psicologia e a biologia, que possuem como tema comum de pesquisa o sistema nervoso - oferece a possibilidade de entender como ocorre o processo de aprendizagem. Embora, para que a aprendizagem aconteça, seja necessário o diálogo entre a neurociência e a pedagogia, pois esta última é a responsável pelos métodos pedagógicos de ensino (Grossi, Lopes e Couto, 2014, p. 28). 
Em linhas gerais, as emoções podem ser entendidas como reações químicas, e também neurais, do organismo em resposta a determinado estímulo e, com probabilidade de ter um início imediato (voluntário ou involuntário), podendo ocorrer antes mesmo que o indivíduo tome consciência e perceba sua mudança fisiológica. Lent (2010) aponta as emoções como muitas e difíceis de classificar, as quais envolvem aspectos como sentimento, reações motoras - características de cada emoção e, ajustes fisiológicos. Assim, o autor descreve que "emoção e razão são as funções mais complexas de que o cérebro humano é capaz" (p. 714). Pinto (2001) acrescenta que emoção é um comportamento reconhecível, derivada de uma reação complexa de estímulo ou pensamento, o qual permite uma interpretação cognitiva e uma experiência subjetiva.

Fato é que as emoções são diretamente influenciadas pelo contexto em que elas ocorrem, desta forma, ao vislumbrar um contexto escolar (e em momentos de ECS - formação de professores), podemos extrair que os processos de ensino e aprendizagem não são meramente cognitivos, mas altamente carregados de emoções, ou seja, as emoções podem ser decodificadas em respostas aos estímulos recebidos, sendo muitas das vezes inconscientes ao agente que a expressa, neste caso os estagiários.

À medida que os organismos adquiriram maior complexidade, as ações "causadas pelo cérebro" necessitaram de um maior processamento intermediário. Outros neurônios foram interpolados entre o neurônio do estímulo e o neurônio da resposta, e variados circuitos paralelos assim se estabeleceram, mas isso não quer dizer que o organismo com esse cérebro mais complexo tivesse necessariamente uma mente. Os cérebros podem apresentar muitos passos que intervêm nos circuitos que fazem a mediação entre 0 estímulo e a resposta, e ainda assim não possuírem uma mente, caso não satisfaçam uma condição essencial: possuir a capacidade de exibir imagens e de ordenar essas imagens num processo chamado pensamento (Damásio, 2000, p. 117, grifo nosso).

Lent (2010) menciona que a partir de manifestações comportamentais e fisiológicas é possível analisar uma emoção - respostas motoras. Este comportamento reconhecível ampara-se em aspectos comunicacionais das emoções, na qual as reações humanas têm extrema relevância, tanto em relação à comunicação verbal (explicitada) quanto na comunicação nãoverbal (implícita/interpretativa). Dentre os sinais de comunicação não-verbal, as expressões faciais se destacam (Damásio, 2000), por terem um papel de transmitir uma informação por meio da expressão emocional de identificação imediatista. Investigações em neurociências têm mostrado que a face humana tem uma função imprescindível de identificar e reconhecer emoções derivadas de sentimentos (Lederman et al., 2007). 
Ekman (2011) dedicou-se a mapear a face humana e desenvolver um método que se utiliza do movimento muscular do indivíduo na identificação de emoções, por outro lado, em um viés neurológico, o português António Damásio também buscou distingue vários tipos de emoções (Damásio, 2000). Contudo, existe uma controvérsia em definir quais e quantas são as emoções humanas. Tanto que em alguns estudos tem-se adotado critérios específicos para identificar as emoções (Santos, 2009). Frente ao arcabouço de ideias, conceitos, taxonomias e pluralidade de contextos, Ekman (2011), a partir da análise de expressão facial distinta e universal, reconhece a existência de sete emoções básicas, podendo ser assim sintetizadas (imagens com base nas linguagens das emoções discutidas pelo autor):

Tristeza: uma emoção das mais negativa que existe, sendo seu estado afetivo caracterizado por sentimentos de insatisfação. Existem muitas palavras sinônimas que descreve uma pessoa triste, por exemplo, atormentado, desapontado, abatido, melancólico, deprimido, desencorajado, enlutado, entre outros. Segundo o autor, alguns exemplos (dentre outros) de expressões faciais que permite reconhecer esta emoção: (i) boca com cantos abaixados; (ii) bochechas sem qualquer movimento; (iii) o olhar abaixado com as pálpebras superiores curvadas e; (iv) os olhos podem umedecer com as lágrimas (pp. 98-124).

Raiva: (ou cólera) uma emoção das mais perigosa, a qual pode ser definida em termos de "pretensão de causar dano e hostilizar a alguém". Em síntese, pode ser manifestada por comportamentos agressivos, podendo chegar a vias de fato (intensidade maior) em um alvo desejável - existe um impulso para avançar. A expressão facial dessa emoção pode se compõe por: (i) sobrancelhas abaixadas e unidas; (ii) o olhar fixo e (iii) o maxilar está firmemente apertado. A boca pode ficar aberta parecendo um quadrado ou pode ficar firmemente fechada, lábio contra lábio (pp. 125-159).

Surpresa: considerada a mais breve de todas as emoções, durando não mais do que poucos segundos - por vezes involuntárias. Derivada de sentimentos e reações relativas a acontecimentos inesperados. Esta emoção pode ser identificada através de modificações faciais muito expressivas e evidentes, como: (i) olhos arregalados; (ii) sobrancelhas erguidas; (iii) boca apertada em forma de elipse e; (iv) queixo elevado (pp. 160-182).
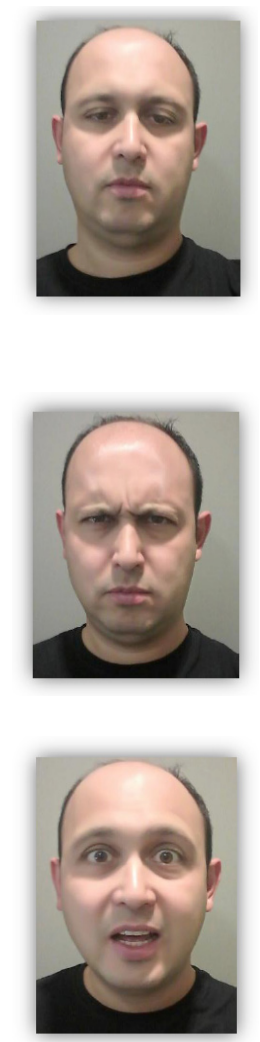
Medo: geralmente emanada de uma sensação de perigo, de um estado de alerta. Dentre as diferentes situações que podem desencadeá-la, está a origem em ameaças físicas ou psicológicas, por exemplo. Algumas expressões faciais que podem ser ocasionadas por essa emoção são: (i) boca esticada horizontalmente para trás; (ii) queixo puxado para trás; (iii) pálpebras superiores levantas, enquanto as inferiores estão tensionadas e; (iv) cabeça ou o corpo se inclina para longe do alvo, como se fosse esconder (pp. 160-182).

Aversão: uma emoção negativa que se coloca, por vezes, como de difícil identificação, sendo provocada por sensações não agradáveis, como um sentimento de repulsa a algo (a alguém em geral configura desprezo). Ekman menciona que as reações de aversão quando intensa podem conduzir a náuseas. Alguns sinais faciais que derivam desta emoção e que pode levar a sua identificação são: (i) raiz do nariz encorrilha para cima; (ii) elevação das bochechas e; (iii) abaixamento das sobrancelhas, criando "pés de galinha" (pp. 183-200).

Desprezo: derivado de um sentimento de superioridade em relação a outra pessoa. Está ligado ao poder, sendo uma expressão negativa e variando em intensidade e força. Segundo Ekman (2011), o desprezo "pode ser frequentemente acompanhado pela raiva". Pode ser identificado a partir de diferentes arquétipos faciais, dentre os quais destacam-se: (i) queixo erguido; (ii) olhos abaixados em direção ao nariz e; (iii) uma parte do canto da boca eleva-se ligeiramente (pp. 183-200).

Felicidade: derivada de um sentimento de satisfação e equilíbrio (físico e psíquico). A expressão de felicidade não especifica um tipo específico (satisfação, alegria...), mas um semblante risonho. É uma expressão positiva, de contentamento. A felicidade pode ser evidenciada por meio dos seguintes sinais faciais (dentre outros): (i) sorriso com os dentes a mostra; (ii) as faces arquitetadas; (iii) área dos olhos apertadas devido aos vincos; (iv) as encurvas entre o nariz e o lábio superior (pp. 201-206).
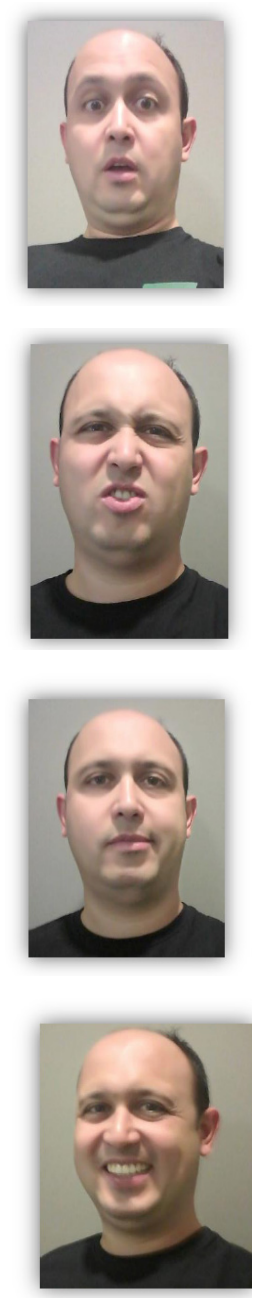

Ekman (2011) revela ainda a possibilidade de interpretação de outras emoções, classificadas por ele como "emoções agradáveis" e por "outras emoções". Descreve como "emoções agradáveis": Alegria, emoção com maior intensidade do que a satisfação ou a felicidade; Diversão, emoção muito agradável, podendo variar de intensidade dependendo das risadas podendo levar até as lágrimas; Contentamento, pode ser identificado por meio da voz e pela face de relaxado ou contente, pois parece tudo certo no mundo; Entusiasmo, emoção que corresponde à novidade ou ao desafio. Alívio, caracteriza-se por quando algo que tinha despertado fortemente se aquieta, acompanhado de um suspiro e a respiração profunda. Êxtase, uma experiência intensa, onde o objetivo é alçando com sucesso. Gratidão, um sujeito sempre proporciona o benefício para o outro. Elevação, a pessoa se 
sente motivada a ser sempre uma pessoa melhor. Por fim, "outras emoções" descritas pelo autor são: Assombro, define pela raridade e o sentimento de dominação por algo incompreensível. Angústia, é quando o sentimento de tristeza persistir por muito tempo, sendo intensificado por meio de algum acontecimento ou ocasião; Ansiedade, ou nervosismo, antecipa situações de perigo que pode ocasionar em sensações desagradáveis, como o coração batendo rápido, medo intenso, aperto no tórax, transpiração e outros. Fato é que grande parte destas emoções têm estrita relação e derivam das emoções básicas, comungando dos mesmos arquétipos faciais de identificação.

As emoções comandam grande parte da vida cotidiana das pessoas. Apesar do crescente arcabouço de pesquisas sobre a neurociência (Christodoulou e Gaab, 2009; Mason, 2009) e da importância da temática emoções para diferentes áreas (psicologia, neurologia, educação, psiquiatria...), é verdade que ainda são poucos os estudos que investigam as emoções no campo da educação (Borrachero et al., 2014), em especial versando sobre a formação de professores e os estágios curriculares.

Grande parte desta falta de conexão entre as áreas reside no fato de que, sobretudo, neurocientistas, ao escreverem sobre educação, direcionam a linguagem a outros neurocientistas. Isso torna a compreensão dificultosa para pessoas que, muitas vezes, não possuem treinamento e conhecimento em conceitos biológicos. Um efeito disso é a pouca ou nenhuma aplicabilidade dos dados neurocientíficos em contextos pedagógicos (Carvalho e Boas, 2018, p. 237).

Segundo Melo e Cañada (2018, p.67) “[...] as emoções influenciam principalmente os conhecimentos sobre conteúdo, alunos, currículo e estratégias de ensino. [...] As causas, positivas e negativas, estão relacionadas principalmente ao conhecimento". Nesse sentido, Schutz e Zembylas (2009) destacam que aproximadamente $50 \%$ dos professores abandonam a carreira nos primeiros cinco anos e, provavelmente, isso se deva às emoções e sentimentos, particularmente no caso das emoções de cunho negativas, pelas implicações ocorridas no processo de ensino e aprendizagem e na realidade escolar (na maioria quando se realiza o ECS), atribuindo-se a diversidade de emoções e sentimentos que os professores sentem ao adentrar na sala de aula.

Aspectos emocionais são de extrema relevância, principalmente na formação inicial de professores, pois podem influenciar definitivamente na carreira docente, em especial no momento formativo dos ECS. Refletir sobre as emoções que demandam desta etapa de formação, pode possibilitar aos formadores novos vieses de atuação e preparação dentro dos cursos universitários, não deixando velada a temática e dando vozes as percepções dos 
licenciandos, futuros professores. Destaca-se que os ECS além de serem uma importante ferramenta pedagógica dentro do processo de formação inicial docente, são excelentes excitadores/provocadores de emoções.

[...] quando os futuros professores iniciam seu estágio de educação universitária, eles têm ideias, concepções, atitudes, valores e emoções sobre a ciência e sobre o modo de aprender e ensinar, fruto dos anos que passaram como escolares e assumir ou rejeitar os papéis dos professores que tinham na sua escola e universidade (Mellado et al., 2014, p. 17).

As emoções explicitadas por Ekman (2011), e descritas ao longo desta comunicação, não se esgotam todas as emoções possíveis de serem manifestadas por um indivíduo, contudo entendemos que nos permite um norte para nossas análises, uma vez que traz descrições para agrupar ou correlacionar possíveis emoções identificadas e não categorizadas pelo referido autor. Deste modo, assumimos os constructos teóricos de Ekman (2011) para a identificação, análise e discussão das emoções que possam derivar dos participantes da presente pesquisa, ou seja, licenciandos de cursos de Física e Ciências Biológicas da UFTM, em situação de ECS.

\section{MARCO TEÓRICO-METODOLÓGICO DA INVESTIGAÇÃO}

A presente pesquisa tem como enfoque abordagem de natureza qualitativa (Bogdan e Biklen, 1994), compreendendo observação e gravação em áudio e vídeo das regências ministradas pelos participantes, licenciandos em situação de estágio supervisionado e, posterior entrevistas semiestruturadas com os mesmos. É importante enfatizar que esta comunicação é um recorte de uma pesquisa de mestrado na qual participaram licenciandos de cinco cursos, Física, Química, Ciências Biológicas, Matemática e Educação do Campo da UFTM. Contudo tendo em vista a extensão do texto, focalizaremos as discussões em um licenciando de Física (EstFis) e um licenciando de Ciências Biológicas (EstCien).

Como marco teórico-metodológico, empregou-se a Entrevista de Explicitação (EDE) (Vermesch, 2003), articulada com recortes das gravações das regências frente a identificação das emoções dos licenciandos em situação de ECS. A EDE é um tipo particular de acompanhamento de entrevistas no qual busca-se uma verbalização introspectiva detalhada das ações realizadas e acompanhadas in loco. Desta forma, a EDE tem sido utilizada em diversos trabalhos que almejam o levantamento de emoções em diferentes contextos, por exemplo, um trabalho nesta vertente realizado por Wykrota (2007), afirma que: 
[Vermersch] propôs como usar a prática da introspecção partindo do princípio que existe uma disjunção entre a lógica da ação e a lógica da conceituação, de modo que a prática da introspecção não requer, necessariamente, conhecimentos científicos exaustivos sobre 0 assunto por quem a pratica. [...] A EDE é assim denominada por, essencialmente, referir-se a um método particular de coleta de verbalização. Trata-se de um conjunto de técnicas de acompanhamento de uma pessoa na exploração, passo a passo, de um momento singular por ela vivenciado, que pode ser útil para ajudá-la a entrar em contato consigo mesma, a acessar conhecimentos implícitos e a promover sua verbalização. O propósito é apoiar essa pessoa no desenvolvimento da experiência tal como foi vivenciada [...] para a experiência representada e verbalizada [...] encorajando-a a entrar e a sustentar um estado de evocação, orientando a percepção desta evocação de modo a explorar e verbalizar detalhes dessa experiência. Desse modo, podem acontecer insights e tomada de consciência de elementos implícitos da vivência, tanto pelo entrevistado como pelo entrevistador (Wykrota, 2007, pp. 78-84, grifo nosso).

No que se refere à gravação em áudio e vídeo das regências, esta é uma técnica que se torna fundamental nesta pesquisa, pois permite revivenciar os momentos, e selecionar cenas para confrontar e discorrer com o estagiário na entrevista após as regências ministradas, de modo a identificar as emoções contidas naquela ação e assim refletir sobre sua prática docente. Como instrumento auxiliar para identificação das diferentes emoções utilizou-se as entrevistas semiestruturadas. Estas foram realizadas após as aulas regências dos estagiários, articulada com as cenas das gravações em áudio e vídeo, de modo a levantar as emoções e os sentimentos explicitados pelos licenciandos.

Destaca-se que nesta comunicação os estágios de regências acompanhados fazem parte da disciplina Orientação e Estágio Curricular Supervisionado II (ECS II), sendo o momento em que o licenciando adentra pela primeira vez em sala de aula e, se depara com a realidade escolar enquanto futuro professor. Os resultados das ações são referentes ao primeiro semestre (2017/1) da disciplina de ECS II, no qual os próprios estagiários escolheram a escola de atuação e as datas das aulas ministradas, juntamente com o professor orientador (Universidade) e professor supervisor (Educação Básica). Especificamente, o ECS foi realizado nos anos finais do Ensino Fundamental ( $6^{\circ}$ ao $9^{\circ}$ ano), em duas escolas da rede públicas da cidade de Uberaba, estado de Minas Gerais, Brasil. Foram acompanhadas e gravadas as regências dos estagiários, onde estes começaram a desenvolver o "Ser professor", assumindo turmas com a competência de um docente, de modo a transparecer suas emoções durante o processo formativo do "aluno" para "professor". 


\section{DECORRÊNCIAS E DISCUSSÕES EMANADAS DO ECS}

Na busca por identificar as emoções expressadas pelos estagiários em Física e em Ciências Biológica (EstFis e EstCien), procuramos identificar cenas que aludissem a alteração emocionais (positivas e negativas), e que refletiam tomadas de decisões frente situações diversas em sala de aula. No decorrer da pesquisa, foram acompanhadas cinco regências (aulas de 50 minutos) do EstFis, o qual decorreu sobre o tema "energia" e, seis regências (aulas de 50 minutos) da EstCien, a qual trabalhou assuntos relacionados a temática "vírus". Devido à grande quantidade de dados (gravações, entrevistas e anotações) e, como forma de exemplificar nossos achados de pesquisa, a seguir apresentamos momentos específicos das regências do EstFis e da EstCien, iniciando pelo estagiário em Física.

Durante o acompanhamento das regências ficou bastante evidente a preocupação e o esforço do EstFis para que os alunos entendessem o que ele havia preparado para a aula. Em diversas ocasiões, a atuação em sala de aula se colocou como intensa, empolgante e, por vezes, culminou em falas acelerada do EstFis, refletindo um estado aparente de extâse, no qual seus objetivos estavam sendo alcançados. Na eminência em iniciar em sala de aula, ficou nítida a angústia do EstFis, ocasionando idas ao banheiro e mãos suando. Segundo Ekman (2011), este estado fisiológico e comportamental pode indicar indícios de situação de stress, derivado de momentos de nervosismo ou até mesmo de medo.

Em sua primeira regência (momento 17 minutos e 23 segundos), um alunx gesticulando com as mãos levantou um questionamento sobre a diferença entre energia cinética e energia potencial. Como forma de interação e socialização com os demais alunos, o EstFis utilizou como estratégia didática a repetição da pergunta e expressou: "Vocês ouviram o que ele [pausa], ela disse?" (EstFis, em regência) (Figura 1a). Percebendo a agitação dos alunos, rapidamente notou que algo estava errado, ou seja, com a forma de tratamento direcionada ao alunx. Não querendo causar constrangimento pelo ocorrido, de pronto pediu desculpas ao alunx. Após esse momento, um grupo de alunas, que sentavam em carteiras mais à frente da sala, começaram a rir fazendo com que (frente ao episódio) o EstFis começasse a gaguejar (Figura 1b), a piscar os olhos indescritivelmente (Figura 1c) e puxar a blusa (Figura 1d) deixando transparecer visivelmente a alteração de seu estado. 


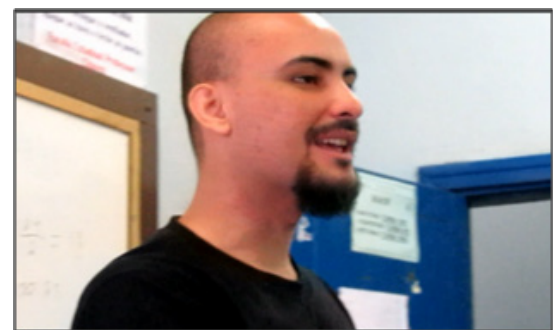

a

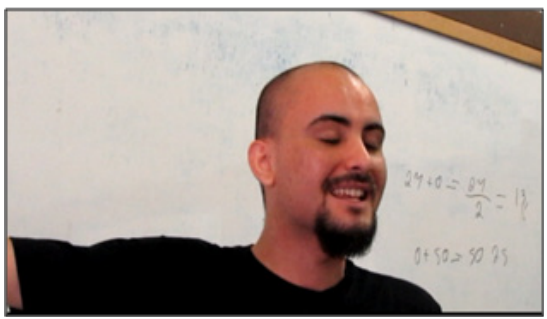

C

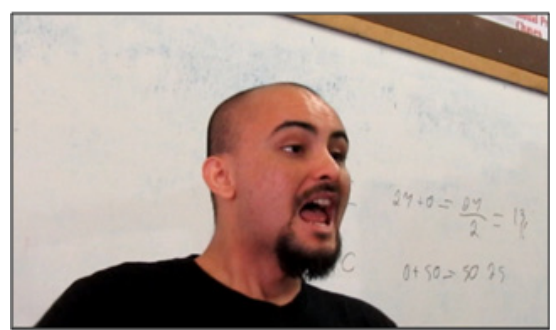

b

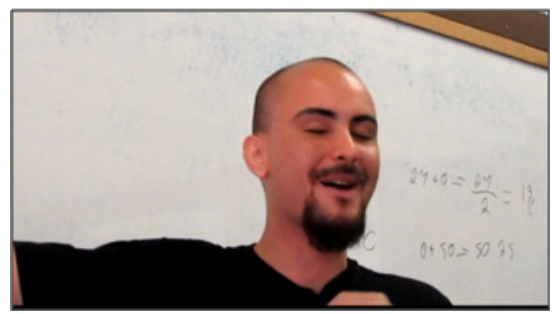

d

Figura 1: Em (a) EstFis ao socializar com a sala a pergunta do alunx. Em (b) EstFis começa a gaguejar durante a explicação. Em (c) pisca os olhos recorrentemente. Em (d) puxa a blusa demonstrando incomodo com a situação vivenciada. Fonte: dos autores.

Após as regências, durante a Entrevista de Explicitação (EDE) ao assistir a cena acima explicitada, o EstFis expressou:

Nessa hora, eu fiquei nervoso mesmo. Uma coisa que aprendi é sempre perguntar o nome da pessoa antes [risos] [...] a gente tem que saber continuar a aula de uma forma discreta, que os alunos não percebam que aconteceu alguma coisa muito cabulosa (EstFis, em entrevista).

Neste episódio, a adoção da EDE possibilitou a confirmação do estado emocional vivenciado pelo EstFis naquele momento. A gravação juntamente com a entrevista permitiu ao EstFis confirmar as emoções surpresa e assombro frente ao que fora vivenciado. Segundo Ekman (2011) surpresa configura-se como uma das emoções mais breve de todas, durando poucos segundos e, a emoção assombro é definida pelo autor como expressão de algo incompreensível. Destaca-se que a situação causou grande incômodo ao EstFis, levando-o a mencionar que, após a aula, realizou uma autorreflexão sobre os fatos. 0 EstFis acredita que perguntar o nome da pessoa antes de socializar com a turma pode ser uma boa estratégia para não passar novamente por este constrangimento. Contudo, mencionou também que apesar de ter ciência de que não poderia deixar transparecer suas emoções aos alunos, isto foi inevitável pois não esperava aquela situação. 
Diversas outras situações trouxeram à tona emoções vivenciadas pelo EstFis no decorrer das regências. Em sua terceira regência (momento 05 minutos e 26 segundos), como estratégia didática, o EstFis dividiu a turma em grupos de cinco alunos cada. Cada grupo ficou responsável ler alguns textos e depois socializar com os demais colegas de sala. Os textos abordavam diferentes tipos de energia: mecânica, térmica, elétrica, química e nuclear. Durante as explicações da atividade o EstFis teve que chamar a atenção dos alunos diversas vezes, pedindo silêncio e trocando alunos de lugar (Figura 2).

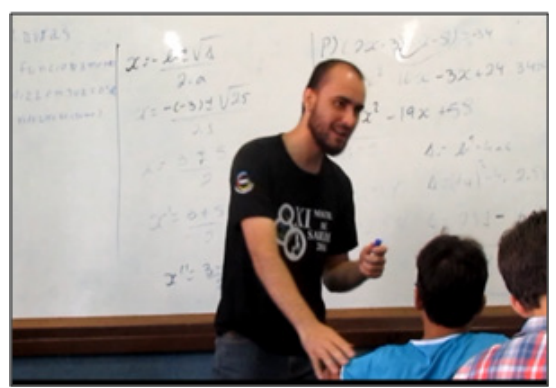

a

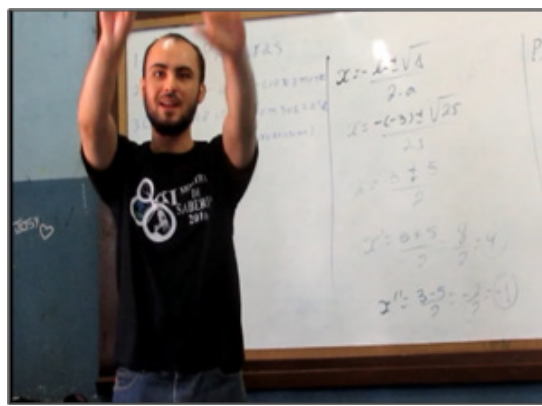

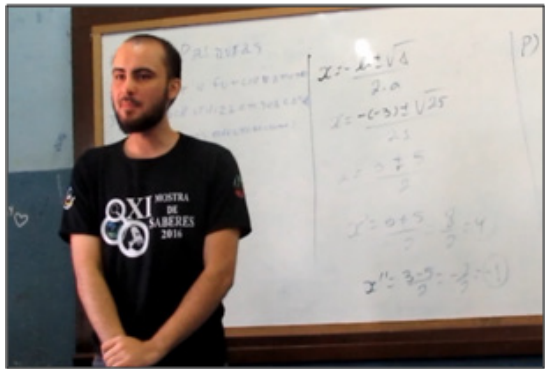

b

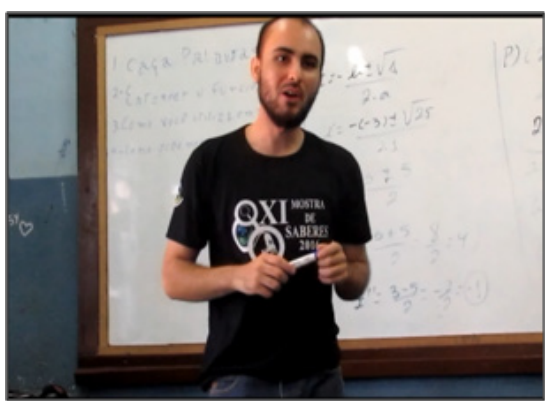

Figura 2:. Em (a) EFis dividindo os alunos em grupo para realizar as atividades. Em (b) momento em que para de falar e começa a demonstrar insatisfação com a sala, devido ao barulho. Em (c) chamando a atenção dos alunos para as explicações. Em (d) tenta retomar as explicações. Fonte: dos autores.

Em entrevista, ao ser indagado sobre esta situação/momento, o EstFis expressa que ficou incomodado com a postura dos alunos. Em uma primeira análise a situação relatada indicava nervosismo por parte do EstFis, contudo ao ver as cenas frente ao EDE o EstFis menciona que a emoção expressada pelo sentimento de nervosismo estava atrelada a sua ansiedade em iniciar as atividades rapidamente com a sala, visto que o tempo de aula estava apertado. Este fato deixou transparecer um sentimento de nervosismo com a situação, então explicita: 
Nervoso a gente fica um pouco. É aquela coisa, chamar a atenção é normal, não tem como ficar muito nervoso com isso, acho que na primeira vez é mais complicado chamar a atenção deles [dos alunos] (EstFis, em entrevista).

Com o início das atividades, nota-se claramente nas gravações a quietude da sala e os alunos passam a trabalhar com os textos entregues pelo EstFis. Sobre este aspecto, o EstFis expressa uma sensação de alívio, derivada do controle da situação. O EstFis considera normal na prática docente os recorrentes pedidos de silêncio para os alunos, visto que são adolescentes. Entretanto, confessa que sendo a primeira vez considera ser difícil lidar com a situação. Acredita, contudo que após o convívio e maior intimidade com a turma a situação se torna mais natural.

Sobre este aspecto, buscando o controle da turma, em sua quarta regência (momento 16 minutos e 31 segundos) novamente tem que parar as explicações para pedir silêncio para os alunos (Figura 3a). Frente a situação e vendo que ninguém obedecia aos pedidos do estagiário, uma aluna grita pedindo silêncio para os colegas. De imediato, nota-se pelas cenas selecionadas que o EstFis fica acanhado e sem saber muito bem o que fazer, arriscando uma pequena risadinha em sua expressão facial, evidenciando a surpresa com a atitude da aluna (Figura $3 b$ ).

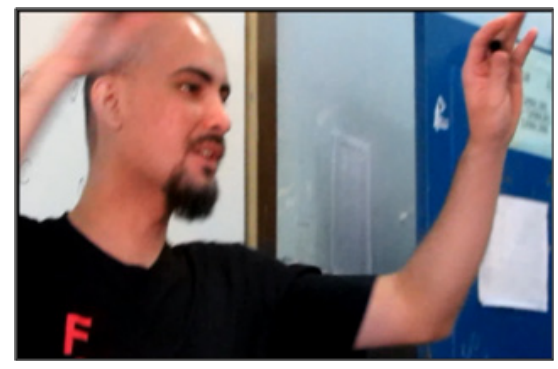

a

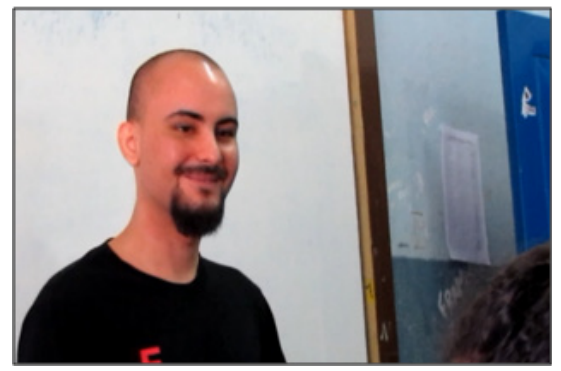

b

Figura 3: Em (a) EstFis ao tentar solicitar silêncio para a turma, percebendo a agitação da sala. Em (b) EstFis esboça uma expressão de surpresa, emitindo uma singela risada em agradecimento a aluna. Fonte: dos autores.

Em entrevista, ao mostrar as cenas para o EstFis e questioná-lo sobre a situação, o mesmo explicita que:

[...] eu assustei na hora [risos], pedindo um silêncio a mais. Também não queria reprender a aluna, falar tipo: "Você está errada" [por gritar]. Não... Agradeci "Valeu, é nós!" [faz agradecimento com as mãos]. Não fiquei frustrado pela a aluna me ajudar não, pois sempre tem alguém que comanda a sala. Agora incomodado com o barulho isso a gente teria que passar mesmo, [pausa] mas é sempre bom manter a ordem (EstFis, em entrevista). 
Ao rever as cenas frente ao EDE e discutir com o EstFis, percebemos a emersão de algumas emoções veladas, como surpresa, alívio e gratidão, uma vez que o EstFis não esperava a reação da aluna, e também por não sabia como agir: agradecer ou reprimir tal atitude, o que nas palavras do estagiário são "ossos do oficio" da profissão docente. Na classificação de Ekman (2011) gratidão pode ser sinônimo um reconhecimento a ação do outro. Em sínteses, algumas das emoções mais frequentes identificadas, por meio da EDE com o EstFis, foram medo, êxtase, surpresa, assombro, ansiedade, alívio e gratidão.

Seguindo a mesma sistemática adotada com o EstFis, acompanhamos a EstCien momentos antes da realização de sua primeira regência. Apesar de se mostrar inquieta para iniciar em sala de aula, ela estava muito entusiasmada sentindo-se preparada para realizar as regências. Mencionou que, apesar de um pouco nervosa, tinha a convicção de que a Universidade oferecia uma boa formação para desempenhar seu papel como futura professora. Esta mistura entre nervosismo e entusiasmo, deixou transparecer um cenário emocional agradável, o que na classificação de Ekman (2011) podemos definir como entusiasmo, ou seja, intimamente ligada à novidade ou ao desafio do novo. Em diversos (e frequentes) momentos durante as regências, a EstCien evidenciava um estado emocional alterado, sendo constante a gesticulação com as mãos, gestos corporais e olhar fixo e/ou arregalados.

Em entrevista, quando reavivadas tais cenas a EstCien explicitou que durante as regências não tinha a noção do quanto arregalava os olhos, assumindo que todas as vezes que fazia esse movimento era porque estava se sentindo estressada ou com raiva por algo que fugia ao planejado. 0 sentimento de estresse provocado, por exemplo, por exaustão física ou emocional pode levar a um estado emocional de raiva, o qual segundo Ekman (2011) se deixa transparecer, dentre outros comportamentos por um olhar fixo e por vezes distante, somado a outros aspectos, como maxilar apertado, boca entreaberta ou firmemente fechada. A seguir apresentamos algumas análises realizadas de situações peculiares das regências ministradas pela EstCien.

Em sua terceira regência (momento 14 minutos e 48 segundos) a EstCien, realizou um experimento onde buscava demonstrar a diferença entre um microscópio e um smartcópio (tipo de microscópio caseiro feito com material de baixo custo e de fácil execução). Para a realização da atividade, os alunos foram divididos em dois grupos, ficando metade em sala de aula, para visualizar algumas células com o auxílio do microscópio e, outra metade no pátio da escola, onde visualizariam as células com o smartcópio. Após todos realizassem as visualizações, deveriam trocar de ambientes de modo a visualizar as células nos dois aparelhos. 0 intuito foi possibilitar a comparação entre as diferentes visualizações. 
Ao iniciar a explicação sobre a visualização de uma célula, a EstCien percebeu que dois alunos começaram a discutir buscando um melhor posicionamento para visualização da célula. Nesse momento, a EstCien interrompeu a explicação e levantou a cabeça pedindo para que os dois alunos parassem com a discussão (Figura 4a). Então, pronunciou "[...] ai ai ai, a briga!" (EstCien, em regência). Na continuação das explicações, a EstCien mostrou-se bastante apreensiva com a situação instaurada, fato visivelmente notado em sua expressão facial (Figura 4b e 4c). Ocorre que os alunos continuaram os insultos mútuos, levando a EstCien a chamar novamente a atenção, de forma mais severa: "Parou, parou!" (EstCien, em regência) (Figura 4d).

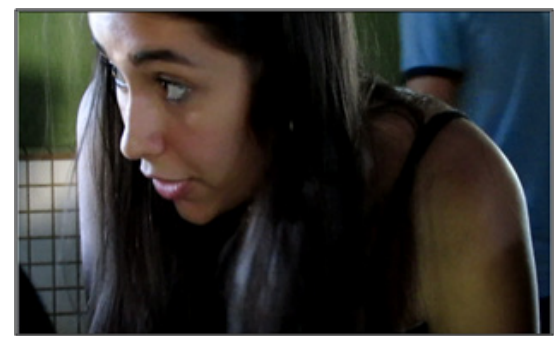

a

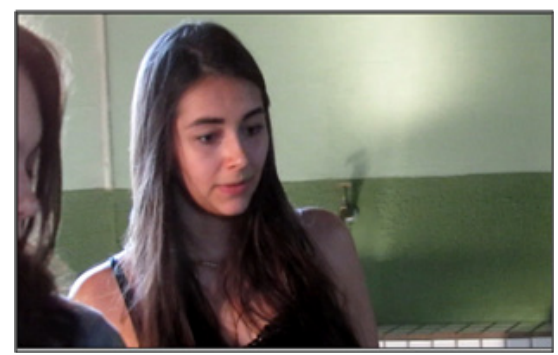

c

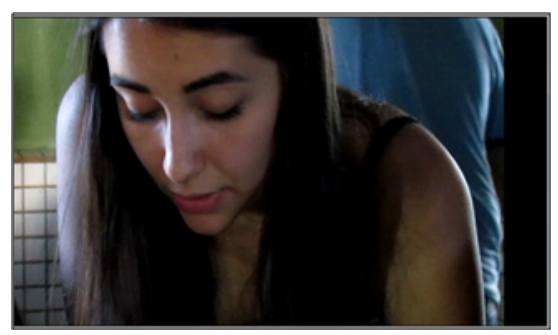

b

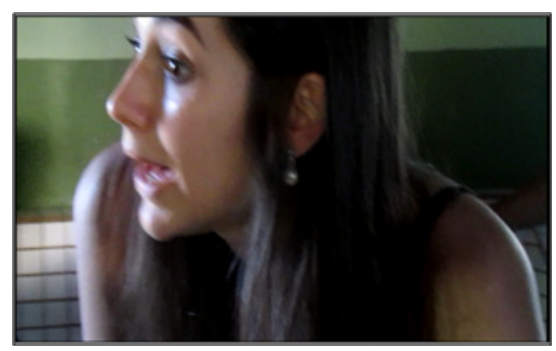

d

Figura 4: Em (a) EstCien interrompe as explicações para chamar a atenção de dois alunos que estavam discutindo. Em (b) e (c) EstCien esboça uma expressão facial apreensiva, devido a situação de indisciplina de alguns alunos. Em (d) EstCien chama atenção de alguns alunos. Fonte: dos autores.

Em entrevista, assistindo as cenas e sendo questionada sobre aqueles momentos, a EstCien explicitou que:

Fiquei com medo deles [dos dois alunos que discutiam] sei lá [risos]. Os alunos poderiam brigar com tapas, porque eles são do $7^{\circ}$ ano e a possibilidade de acontecer isso seria maior, por isso que separei os dois [alunos], pois eles estavam um do lado do outro, por isso coloquei um de cá e deixei ela de lá [mostrando os lugares], pelo menos o contato físico [risos] evitar o contato físico (EstCien, em entrevista). 
A situação vivenciada pela EstCien deixou transparecer a emoção de medo, a qual pode derivar de um estado de alerta, sendo este corroborado por ela durante a EDE. A EstCien relatou ainda em entrevista que sua apreensão estava atrelada à sentimentos de ansiedade e nervosismo, pelo fato de haver a possibilidade de vias de fato (contato físico) entre os alunos, ou seja, intimamente ligada ao medo relatado. Este tipo de sentimento é comum em vivências didáticas, principalmente para os estagiários, reforçando a importância deste momento pedagógico para a formação inicial de professores. Como relatado, que em seu primeiro com a sala de aula, a EstCien se deparou com uma situação na qual não sabia como resolver, deixando vir à tona diferentes sentimentos e emoções, comuns no início de carreira. Contudo, seguindo a mesma dinâmica outrora evidenciada pelo EstFis, a estagiária também mencionou que após a regência fez uma autorreflexão buscando soluções para o que havia vivenciado.

Outro momento de destaque, refere-se ao final da sexta regência da EstCien (momento 42 minutos e 26 segundos). A aula foi ministrada no último horário do turno e os alunos estavam agitados para irem embora para casa, sendo necessário a estagiária chamar a atenção dos alunos várias vezes. Em determinado momento da aula, a EstCien pediu silêncio para a turma, contudo um aluno (mais agitado) levantou e começou a passear pela sala de aula. Para que esse aluno ficasse quieto, a EstCien começou a gesticular com os braços, fazendo o gesto de silêncio com o dedo e som com a boca (Figura 5a). Não obtendo sucesso, chamou a atenção dos alunos gesticulando com as mãos novamente, uma vez que já havia chamado a atenção de um aluno quatro vezes (Figura $5 b$ ). Outra estratégia utilizada foi solicitar ao aluno que mudasse de carteira, sentando na frente da sala de aula. Essa mudança não agradou o aluno, o qual começou a rebater a decisão da EstCien, iniciando uma discussão (Figura 5c). Com a discussão, a EstCien fica com as emoções visivelmente alteradas, estando com a expressão facial séria e passando a cruzar os braços (Figura 5d).

Assistindo as cenas selecionadas e em EDE, a EstCien ao ser questionada sobre esses episódios e os sentimentos aflorados pela sua expressão facial e gestual, confirma que:

Acho que faltou eu ser um pouco mais rígida, de falar "cala a boca e vem" [...], mas também acho que não posso usar essas palavras em sala de aula [risos]. Senti raiva novamente, porque eu já tinha chamado à atenção dele [0 aluno] várias e várias vezes e, mesmo assim, quando pedi para mudar de lugar o aluno responde: "Eu não estou conversando" [imitando o aluno]. [Essa situação] deixa a gente brava sim, deixa a gente [pausa] mexe com 0 estado emocional, porque você chamar a atenção do mesmo aluno, cinco, seis vezes, é cansativo. Naquele dia, queria somente terminar a aula e ir embora para a casa (EstCien, em entrevista). 


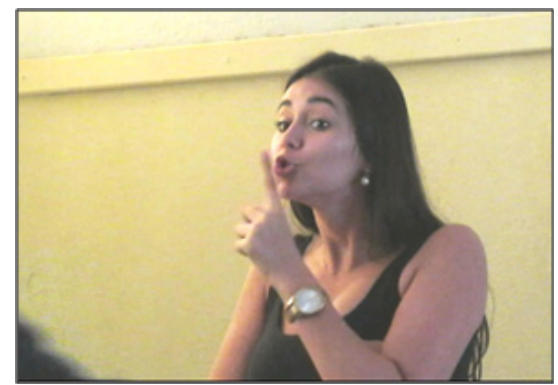

a

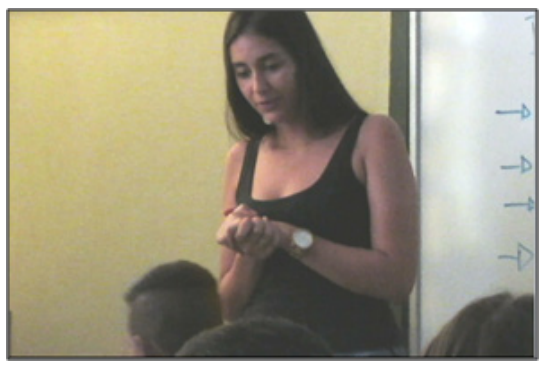

c

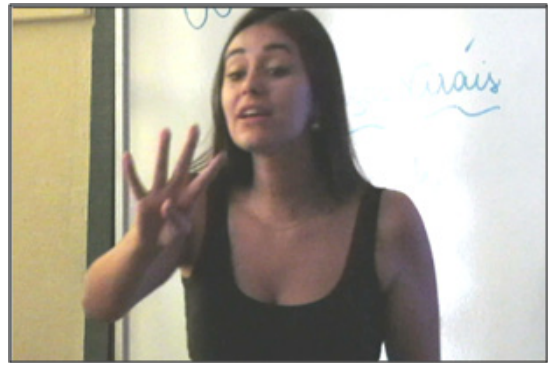

b

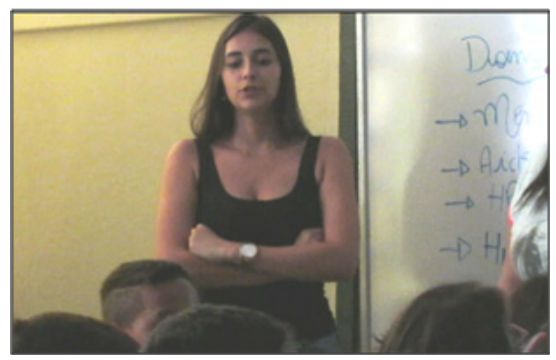

d

Figura 5: Em (a) EstCien pede silêncio e chama a atenção de um aluno que estava agitado. Em (b) EstCien chama novamente a atenção dos alunos gesticulando com as mãos. Em (c) EstCien começa a discutir com um aluno que não queria mudar de lugar na sala de aula. Em (d) EstCien deixa transparecer um estado emocional alterado, sentindo-se incomodada com a situação. Fonte: dos autores.

Em uma análise preliminar, antes da entrevista com a EstCien, havíamos extraído a possibilidade de um sentimento de frustração por parte da EstCien, contudo ao assistir as cenas com a estagiária em EDE, a mesma mencionou que sentia tristeza e ao mesmo tempo raiva, amparada em sentimentos de nervosismo e angústia na situação vivenciada. Esta mistura entre tristeza e raiva deixou transparecer um cenário emocional negativo, o que na classificação de Ekman (2011) está intimamente ligada a um sentimento de insatisfação. Em sua autorreflexão, a EstCien relatou ainda que poderia ter sido mais rígida, mas faltou experiência para gerenciar a situação. Acreditamos que houve uma preocupação com os limites e com as palavras a serem pronunciadas (ou não) frente a discussão com o aluno em sala de aula. Uma constatação plenamente aceitável visto que se trata de uma professora em início de carreira, em situação de estágio.

Ademais, a emoção tristeza surge nas falas da EstCien quando ela menciona que gostaria que a aula terminasse e, então, ir embora para a casa. Notamos ao final das regências que atuar como professora regente ocasionou um grande desgaste emocional e psicológico, confirmado nas 
falas da EstCien. Entendemos que as dificuldades vividas e sentidas pela EstCien evidenciam a complexidade da profissão docente, principalmente para o professor em formação, onde surgem demasiadas emoções, que podem afetar no seguimento da carreira. Em sínteses, algumas das emoções mais frequentes identificadas, por meio da EDE com a EstCien foram entusiasmo, raiva, ansiedade, medo e tristeza.

\section{CONSIDERAÇÕES FINAIS}

Corroboramos das palavras de Mellado et al., (2014, p. 20) de que "na formação inicial, as primeiras experiências de ensino [...] são emocionalmente muito fortes e podem ser traumáticas para os futuros professores, que nesta fase são especialmente vulneráveis". Assim, um dos maiores desafios para os estagiários ao adentrar na realidade escolar é saber lidar com as emoções que surgem da pratica docente.

Nesta apresentação, um recorte de pesquisa, buscamos levantar e discutir as emoções de futuros professores em situação de ECS, em suas primeiras vivências didáticas em salas de aula. Vimos que as emoções tipicamente entendidas como negativas, como medo e raiva, se sobressaíram sobre as emoções positivas, como gratidão e êxtase, no entanto identificamos também outras emoções em nosso estudo, como medo, surpresa, ansiedade, tristeza, nervosismo, angústia e raiva. Frente a identificação de tais emoções, entendemos que a neurociência, emoções e a formação de professores são diálogos necessários e não se esgota com tais análises.

Por fim, esperamos que os resultados apresentados possam ser chamariz para futuras discussões sobre a temática. Ademais, tais discussões podem fornecer subsídios para que outros investigadores maximizem as pesquisas relacionadas a neurociências frente a formação inicial de professores e os desafios a serem enfrentados em início de carreira. Agradecemos aos participantes da pesquisa (EstFis e EstCien) por aceitarem participar e autorizarem este trabalho de pesquisa e a Coordenação de Aperfeiçoamento de Pessoal de Nível Superior (CAPES) pelo apoio. Destaca-se que esta investigação foi aprovada pelo Comitê de Ética em Pesquisa da UFTM, sob o número CAAE: 62201416.3.0000.5154. 


\section{REFERÊNCIAS}

Bogdan, R., \& Biklen, S. (1994) Características da investigação qualitativa. In: Investigação qualitativa em educação: uma introdução à teoria e aos métodos. Porto, Porto Editora.

Borrachero, A. B., Brígido, M., Mellado, L., Costillo. E. Y \& Mellado, V. (2014). Emotions in prospective secondary teachers when teaching science content, distinguishing by gender. Research in Science \& Technological Education, 32(2), 182-215.

Bortoli, B \& Teruya, T. K. (2017). Neurociência e Educação: os percalços e possibilidades de um caminho em construção. Imagens da Educação. 7(1), 70-77.

Brasil (1996). Lei de Diretrizes e Bases da Educação Brasileira (LDB), n. 9.394, de 20 de dezembro de 1996. Ministério da Educação (MEC). Recuperado de https://www. planalto.gov.br/ccivil 03/Leis/L9394.htm

Brasil (2015). Diretrizes Curriculares Nacionais para a Formação de Professores da Educação Básica.... Resolução CNE 2/2015, de 02 de julho de 2015. Conselho Nacional de Educação. Recuperado de http://portal.mec.gov.br/index.php?option=com docman\&view=download\&alias=17719-res-cne-cp-002-03072015\&category slug=julho-2015-pdf\&ltemid=30192.

Carvalho, F. A. H. (2011). Neurociências e educação: uma articulação necessária na formação docente. Trab. Educ. Saúde, 8(3), 537-550.

Carvalho, D., \& Boas, C. A. V. (2018). Neurociências e formação de professores: reflexos na educação e economia. Ensaio: avaliação e políticas públicas em Educação, 26 (98), 231-247.

Christodoulou, J. A.; \& Gaab, N. (2009). Using and misusing neuroscience in education-related research. Cortex, 45(4), 555-557.

Costa, R. A. B., \& Gonçalves, T. O. (2004). Prática de Ensino: Encontros, Desencontros e Reencontros de uma Experiência. In: Encontro Nacional De Educação Matemática. Recife, PE, 2004. Recuperado de: http:// www.sbem.com.br/files/viii/pdf/07/ CC60475200144.pdf

Damásio, A. (2000). O erro de Descartes. Emoção, razão e o cérebro humano. São Paulo: Cia das Letras.

Ekman, P. (2011). A linguagem das emoções. (Carlos Szlak, Trad.). São Paulo: Lua de papel.

Gomes, A. \& Colombo Junior, P. D. (2018). A produção acadêmica sobre estágio curricular supervisionado e a formação inicial de professores: uma análise a partir de revistas "Qualis A/Educação/Capes". Revista Triângulo, 11(1), 163-180.

Grossi, M. G. R., Lopes, A. M., \& Couto, P. A. (2014). A neurociência na formação de professores: um estudo da realidade brasileira. Revista da FAEEBA - Educação e Contemporaneidade, 23(41), 27-40.

Lent, R. (2010). Cem bilhões de neurônios: conceitos fundamentais da neurociência. (2. Ed) São Paulo: Atheneu.

Lederman, S., Klatzky, R., Abramowicz, A., Salsman, K., Kitada, R. \& Hamilton, C. (2007). Haptic Recognition of Static and Dynamic Expressions of Emotion in the Live Face. Psychological Science, 18(2), 158-164. 
Mason, L. (2009). Bridging neuroscience and education: a two-way path is possible. Cortex, 45(1), 548-549.

Mellado, V., Borrachero, A. B, Brígido, M., Melo, L.V., Dávila, M. A., Cañada, F., Conde, M. C., Costillo, E., Cubero, J., Esteban, R., Martínez, G, Ruiz, C., \& Sánchez J. (2014). Las emociones en la enseñanza de las ciencias. Enseñanza de las Ciencias, 32(3), 11-36.

Melo, L., \& Cañada, F. (2018). Emociones que emergen durante el análisis del conocimiento didáctico del contenido sobre el campo eléctrico. Ciência \& Educação, 24(1), 57-70.

Murray, E. J. (1973). Motivação e Emoção. (3. Ed). Rio de Janeiro: Zahar.

Pinto, A. (2001). Psicologia geral. Lisboa: Universidade Aberta.

Santos, C. S. V. (2009). Psicofisiologia das Emoções Básicas: Estudo Empírico com Toxicodependentes em Tratamento (Dissertação de Mestrado). Universidade Fernando Pessoa, Porto, Portugal, Brasil.

Schutz, P. A, \& Zembylas, M. (2009). Introduction to Advances in Teacher Emotion research: the impact in teachers' lives. In: Schutz, P. A; Schutz, P.A.; Zembylas, M. Advances in Teacher Emotion Research: The Impact on Teachers' Lives. New York: Springer, p. 3-73.

Shulman, L. (2015). PCK: its genesis and exodus. In: Berry, A.; Friedrichsen, P.; Loughran, J. (Ed.). Re-examining pedagogical content knowledge in science education. New York: Routledge, p. 3-13.

Strongman, K. T. (2004). A psicologia da emoção. Lisboa: Climepsi.

Vermersch, P. (2003). L'entretien d'explicitation. (4. ed). Issy-les-Molineaux, ESF: Fr.

Wykrota, J. L. M. (2007). Aspectos emocionais de procedimentos de ensino de professores de ciências do ensino médio (Tese de Doutorado). Universidade Federal de Minas Gerais, Belo Horizonte, MG, Brasil. 